\title{
Anti-asthmatic activities in mycelial extract and culture filtrate of Cordyceps sphecocephala J201
}

\author{
JIN-CHUL HEO $^{1 *}$, SUNG-HEE NAM ${ }^{4 *}$, DONG-YOON NAM ${ }^{2}$, JONG-GUK KIM $^{3}$, \\ KWANG-GIL LEE ${ }^{4}$, JOO-HONG YEO ${ }^{4}, \mathrm{CHEOL-SIK} \mathrm{YOON}^{5}, \mathrm{CHUL}^{-H O N G ~ P A R K}{ }^{2}$ and SANG-HAN LEE ${ }^{1,2}$ \\ ${ }^{1}$ Food \& Bio-Industry Research Institute, Departments of ${ }^{2}$ Food Science \& Biotechnology, and ${ }^{3}$ Microbiology, \\ Graduate School, Kyungpook National University, Daegu 702-701; ${ }^{4}$ Department of Agricultural Biology, National \\ Advanced Institute of Science \& Technology, RDA, Suwon 441-707; ${ }^{5}$ Mycoplus Co., Ltd., Uiwang 437-820, Korea
}

Received March 2, 2010; Accepted May 3, 2010

DOI: 10.3892/ijmm_00000472

\begin{abstract}
This study investigated the effects of mycelial extract and culture filtrate of Cordyceps sphecocephala J201 on airway hyper-responsiveness, pulmonary immune cell infiltration, and Th2 cytokine expression in animal models of asthma. After Concanavalin A (Con A) activation of mouse primary spleen cells, the IL-4 and IL-13 cytokine expression were significantly decreased in the presence of the mycelial extract and culture filtrate of Cordyceps sphecocephala J201. The asthma model was induced by sensitization to ovalbumin by intraperitoneal (i.p.) injection treatment in mice. The Cordyceps sphecocephala J201 mycelial extract was injected in order to assess the effects of anti-asthmatic activity by comparing lung cell infiltration in ovalbumin-induced asthmatic mice. The results revealed that the increased IL-4, IL-13 and IL-25 expression were controlled by the mycelial extract and culture filtrate of Cordyceps sphecocephala J201, indicating that the extracts reduced the undesirable immune responses and/or cytokine expression exhibited in asthma.
\end{abstract}

\section{Introduction}

It is well known that asthma occurs from the immune system's overreaction to bronchial hyperinflammation, which is increasingly widespread by industrial development and urbanization $(1,2)$. Immune cells that trigger asthma in $\mathrm{T}$ cells are divided into Th1 and Th2 cells during $\mathrm{T}$ cell differentiation (3). Th1 cells are associated with inflammatory bowel disease (IBD)-related disorders, whereas Th2 cells are associated with autoimmune diseases including asthma $(4,5)$.

Correspondence to: Professor Sang-Han Lee, Department of Food Science and Biotechnology, Kyungpook National University, Daegu 702-701, Korea

E-mail: sang@knu.ac.kr

*Contributed equally

Key words: Cordyceps sphecocephala J201, mycelial extract, culture filtrate, asthma, airway hyper-responsiveness
Research and treatment have given useful asthma preventive medicaments, such as steroid-like drugs for immune disorders (6). Nevertheless, the drugs could relax the stiff muscles and reduce the activation of immune cells (7). As the main target of the drug directly induces the reduction of immune hyper-sensitivity reactions, the inflammatory response of cells signaling to the specific target is focused on the treatment of asthma $(8,9)$. Interleukin-4 (IL-4) and interleukin-13 (IL-13) are the main immunomodulators to induce the autoimmune responses that are excessively secreted by stimulated Th2 cells, moreover, following that the immunoglobulin $\mathrm{E}(\mathrm{IgE})$ and histamine produced by nascent mast cells increases their levels around the bronchial epithelial cells, although these events make the symptoms acute (3). Asthma, atopic dermatitis, and rhinitis that are known to go through a similar signaling process on hyper-responsive symptoms around the epithelial tissues have similar molecular events (10-12).

Cordyceps is traditionally used in Korea, China, and Japan, for the ethnopharmacological treatment of glucose metabolism, cancer, and hypocholesterolemia (13-17). Moreover, tyrosinase-inhibitory activities from Cordyceps extracts exhibit a suppressing effect of melanin production (18). Additionally, anti-depressant, anti-oxidation, hepatoprotective, anti-diabetic, and anti-aging activities from various extracts of Cordyceps exhibited a wide range of bioactivity in vitro, as well as in vivo (19-24).

In this study, we found that the mycelial extract and culture filtrate of Cordyceps sphecocephala J201 have potential in alleviating IL-4, and IL-13 activity in vitro, suggesting that the extract exhibits anti-hypersensitivity. Additionally, we discovered that the mycelial extract and culture filtrates from the Cordyceps sphecocephala J201 control immune activities by balancing the Th1/Th2 cell numbers, which is closely associated with the inhibition of asthma symptoms, suggesting that the extracts could be used for the development of preventive anti-asthmatic food biomaterials and/or nutraceuticals.

\section{Materials and methods}

Materials and reagents. Montelukast was generously gifted by Merck \& Co., Inc., Whitehouse Station, NJ, USA. All other 
materials were of commercial grade. Ovalbumin (OVA; $100 \mu \mathrm{g} / \mathrm{ml}$ in saline) was sterile filtered, mixed with an equal volume of $10 \%(\mathrm{w} / \mathrm{v})$ aluminum potassium phosphate (alum; Sigma), and the $\mathrm{pH}$ was adjusted to 6.5 with $10 \mathrm{~N}$ solution of $\mathrm{NaOH}$. The amount of IL-4 and IL-13 was measured by each ELISA (Product nos. SM400B and SM1300CB, R\&D Systems, Minneapolis, MN, USA) kit. IL-25 Ab was obtained from R\&D Systems (Product No.: AF1399) for immunohistochemistry. 1,1-Diphenyl-2-picrylhydrazyl (DPPH), $\mathrm{FeCl}_{3} \cdot 6 \mathrm{H}_{2} \mathrm{O}$, $\mathrm{C}_{2} \mathrm{H}_{3} \mathrm{NaO}_{2} \cdot 3 \mathrm{H}_{2} \mathrm{O}, 2,4,6$ - tripyridyl-s-triazine (TPTZ), and ascorbic acid were purchased from Sigma Aldrich Chemical Co., Ltd. (St. Louis, MO, USA).

Culture, separation, and microscopic observation of Cordyceps sp. The strain Cordyceps sphecocephala J201 was collected from the Sorak Mountain in Korea and has been preserved in the Entomopathogenic Fungus Collection Center of Department of Agricultural Biology, National Advanced Institute of Science and Technology, RDA, Suwon, Korea. The strain was cultured and isolated in PDA medium (potato dextrose $24 \mathrm{~g}$, agar $15 \mathrm{~g}$, distilled water 1 liter) at $25^{\circ} \mathrm{C}$ for 2 weeks. After full growth of mycelial proliferation, the culture supernatants were centrifuged and divided two parts: mycelial extract and culture filtrate (25). The dried mycelial extract and culture filtrate were then freeze-dried under a vacuum evaporator. The freeze-dried powder was dissolved in phosphate-buffered saline (PBS) prior to use (26). The mycelial morphology was photographed by a scanning electron microscope, as describe elsewhere (27).

Anti-oxidant activities and cytotoxicity. The DPPH method was used for evaluation of the free radical-scavenging activity of the mycelia extract and culture filtrate. Briefly, a $0.4 \mathrm{mM}$ solution of DPPH in 50\% ethanol was prepared and $200 \mu 1$ of this solution was added to $2 \mu 1$ of a differential concentration of the samples. The mixture was shaken vigorously and allowed to stand at room temperature for $30 \mathrm{~min}$ (28). Then, the absorbance was measured at $517 \mathrm{~nm}$ in a multilabel counter (Victor3, PerkinElmer, Waltham, MA, USA) (13). Ferric reducing antioxidant power (FRAP) assay was also carried out as describe elsewhere (28), with a slight modification. Briefly, the FRAP reagent contained $2.5 \mathrm{ml}$ of $10 \mathrm{mM}$ tripyridyltriazine (FRAP) solution in $10 \mathrm{mM} \mathrm{HCl}$ plus $2.5 \mathrm{ml}$ of $20 \mathrm{mM} \mathrm{FeCl}_{3}$ and $25 \mathrm{ml}$ of $0.3 \mathrm{M}$ acetate buffer, $\mathrm{pH} 3.6$, was freshly prepared. The absorption of the reaction mixture was measured at $595 \mathrm{~nm}$. Ascorbic acid was also tested under the same concentration as a standard antioxidant compound. For the cytotoxicity assay, RAW264.7 cells were collected and incubated into 96-well flat-bottom microplates at the counting of $10^{4} /$ well cells. After $24 \mathrm{~h}$, the mycelial extract and culture filtrate and montelukast were treated with $0,1,10$ and $100 \mu \mathrm{g} / \mathrm{ml}$ for $24 \mathrm{~h}$. Then $10 \mu \mathrm{l}$ of CCK-8 (Dojindo, Gaithersburg, MD, USA) solution (dehydrogenase activity detection) was added to each well, the plate was incubated for $1 \mathrm{~h}$ in the incubator, and the absorbance measured at $450 \mathrm{~nm}$ using a microplate reader (Victor3, PerkinElmer) (29).

Activated spleen cell cultures and cytokine measurement. Separation of mouse spleen cells in primary culture from

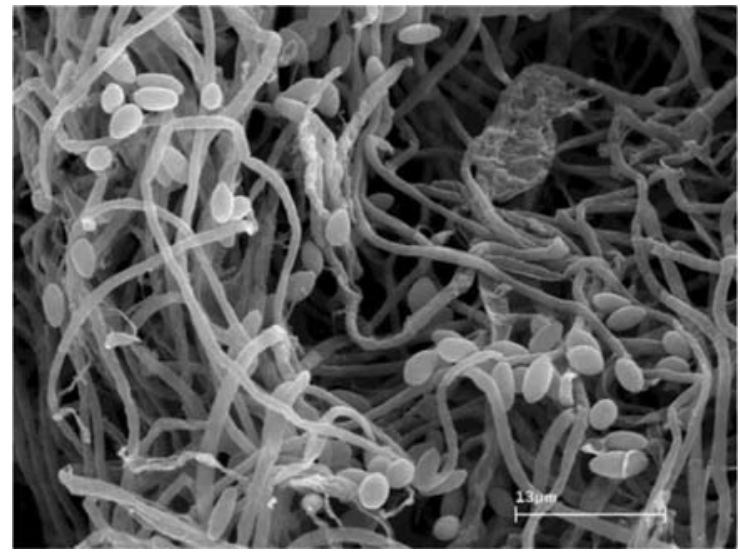

Figure 1. Morphology of mycelial growth of Cordyceps sphecocephala J201. Bar represents $13 \mu \mathrm{m}$.

Balb/C (male, 10 weeks, Samtaco Korea, Osan, Korea) was carried out as follows: the mouse spleen was dissected and crushed on a clean bench, splenocytes were washed 3 times in tissue culture medium while the fragments were allowed to settle, and then the splenocytes were carefully aspirated from the cellular suspension. Concanavalin A (Con A: $3 \mu \mathrm{g} / \mathrm{ml}$ ) was added to activate the total cells following culture for $48 \mathrm{~h}$. Next, various concentrations of aqueous mycelial extract (50 $\mu \mathrm{l} /$ $\mathrm{ml})$ or culture filtrate $(50 \mu \mathrm{l} / \mathrm{ml})$ of Cordyceps sphecocephala J201 were added for $24 \mathrm{~h}$.

Animal experiment and care. All the procedures were performed in compliance with the Guiding Principles in the Care and Use of Animals (National Research Council, 1996) and in-house guidelines of the University (29). In brief, sixweek-old male C57BL/6 mice, weighing between 22-25 g, were purchased from Samtaco Korea, and were fed a commercial diet (Samtaco Korea) and water ad libitum. The animals were housed under a 12-h light/dark cycle at a temperature of $22 \pm 1^{\circ} \mathrm{C}$ and a humidity of $50 \pm 5 \%$. We strictly kept the rules and in-house guidelines for animal experiments including ethical care under the guidance of the University Committee. Animals were allowed to acclimate to the laboratory environment for at least one week prior to the experiments. The number of each experimental group was limited to five.

An asthmatic animal model and immunohistochemistry. The mycelial extract and culture filtrate of Cordyceps sphecocephala J201 was conducted using an ovalbumin-induced animal model for evaluation of anti-asthmatic activity. Mice (C57BL/6, 6 weeks, male) were conducted by spraying with ovalbumin (OVA; $100 \mu \mathrm{g} / \mathrm{ml}$ in saline). In the case of sample treatment, mycelia extract and culture filtrate of Cordyceps sphecocephala J201 were administered 3 times at a volume of $500 \mu \mathrm{l}$ of each oral dose. After the schedule, the lung was cut out to conduct hematoxylin and eosin (H\&E) or Periodic acid Schiff (PAS) staining. Using an optical microscope, we observed the intensity of the symptoms and thereafter evaluated the amount of IL-4, and IL-13 in the plasma or IL-17E in lung tissues was measured using the ELISA method (28) or immunohistochemistry (30). For the IL-25 
A

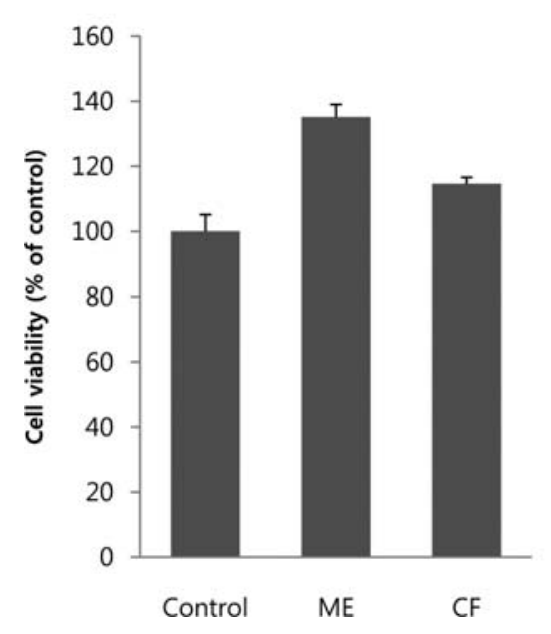

B

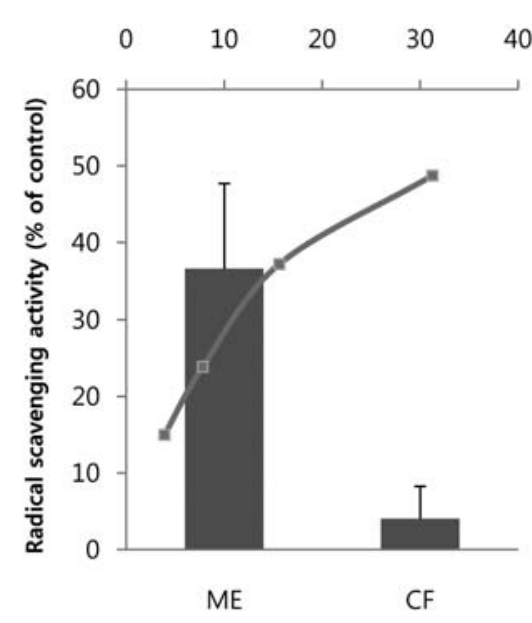

C

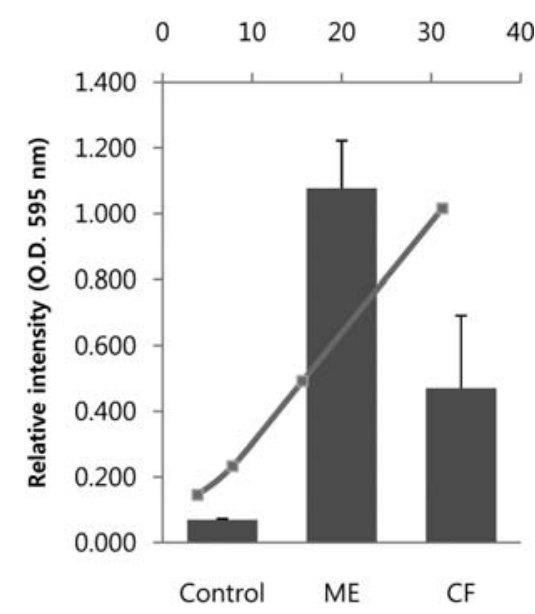

Figure 2. Comparison of cytotoxicity and antioxidant activity. (A) Cell viability in RAW264.7 cells. Mycelial extract (ME) and culture filtrate (CF) of Cordyceps sphecocephala J201 was treated in RAW264.7 cells into 96-well flat-bottom microplates at the counting of $10^{4} / \mathrm{ml}$ cells. After $24 \mathrm{~h}$, the mycelial extract and culture filtrate were treated with $0,1,10$ and $100 \mu \mathrm{g} / \mathrm{ml}$ for $24 \mathrm{~h}$, then CCK-8 kit was used for the cytotoxicity activity by measuring the absorbance at $450 \mathrm{~nm}$ using a microplate reader. (B) Change of radical scavenging capacity of samples was measured at $517 \mathrm{~nm}$ in a multilabel counter as described in Materials and methods. (C) Ferric reducing antioxidant power (FRAP) assay. See details in Materials and methods. Ascorbic acid was tested under the same concentration as a standard antioxidant compound.

expression, we performed an immunohistochemical analysis method (31) with a slight modification.

Statistical analysis. Data were expressed as the means \pm standard deviation. Statistical significance was determined by the Student's $t$-test for independent means using the Microsoft Excel program (32). The critical level for significance was set at $\mathrm{P}<0.05$ or $\mathrm{P}<0.001$.

\section{Results and Discussion}

Cordyceps is an invaluable medicinal mushroom that is called DongChungHaCho (winter worm summer grass) in Korean. It is commonly used to hamper cancer cell growth, and soothe the lung, heart and kidney. For a long time, in Far-East Oriental medicine, it was used to mediate homeostasis in the body, and for the purposes of tonic food and herbal medicine as functional biomaterials. In a previous study, we isolated various Cordyceps and identified one of the strains as Cordyceps sphecocephala J201. The morphology of the selected strain has a classical feature of mycelial growth that is common in entomopathogenic fungus (Fig. 1). In this study, we optimized the maintenance medium of Cordyceps sphecocephala J201 (data not shown), and investigated the biological activities of the mycelial extract and culture filtrate of that strain, in few strains were studied for anti-asthmatic efficacy and their cytotoxicity of the extracts.

To assess the cytotoxicity of mycelial extract and culture filtrate of Cordyceps sphecocephala J201, we used RAW264.7 cells, and measured the cell proliferation by a CCK-8 kit. As a result, $\sim 20 \%$ of cell proliferation was achieved by the addition of culture extract (data not shown). In an earlier study, a component of Cordyceps sphecocephala, the PPP (polysaccharide-peptide complexes) induce DNA fragmentation in the cancer cells, which caused cells to die by caspase- 3 and $\mathrm{Bcl}-2 / \mathrm{Bax}$ by expressing various proteins. On the other hand, human hepatocarcinoma (HepG2) and neuroblastoma (SK-N$\mathrm{SH})$ cells are not known to exhibit toxic effects with treatment (14). Due to differences between cell populations, Cordyceps sphecocephala J201 cultures did not show any toxicity in the cells, whereas the increase of proliferation exhibits the potential activity of cell growth promotion. In particular, the active ingredient in DongChungHaCho's polysaccharide is known to activate the immune cells (33).

The immature T helper cell subset has two kinds of cells: Th1 and Th2 cells. These cells depend on the differentiation and development during $\mathrm{T}$ cell activation (3). It is evident that if Th1 cells have larger numbers than Th2 cells, it may cause inflammatory bowel diseases (IBDs), Crohn's disease, and ulcerative colitis, whereas, the reverse condition of cell numbers may achieve hyper-responsiveness in asthma, atopic dermatitis, and rhinitis (2). We might measure Th1 or Th2 cells with specific biomarkers, thereafter, specific markers can be regulated through their homeostasis in Th specific cell numbers by preventive treatment. For these reasons, we tested whether or not the extracts from the Cordyceps sphecocephala $\mathrm{J} 201$ regulate asthmatic symptoms. We prepared mouse spleen cells, and treated Con A $(3 \mu \mathrm{g} / \mathrm{ml})$ in order to activate the Th2 cells in vitro. As shown in Fig. 3A, there is low amount of IL-4 level $(<500 \mathrm{pg} / \mathrm{ml})$ in the control group, but Con A-induced mice exhibited an 8.5-fold increase in the IL-4 expression level. Interestingly, by the treatment of mycelial extract and culture filtrate, the IL-4 level was dramatically reduced to a control level. In the same pattern, the IL-13 activity was also checked. The elevated IL-13 level was also alleviated by the treatment to the control level, indicating that the asthmatic induction was hindered by the extracts of Cordyceps sphecocephala J201 in Th2 cell numbers (Fig. 3A and B).

The levels of IL-4 and IL-13 in the Th2 cells and in serum are associated with asthmatic symptoms that are the most important phenotype markers in peripheral lung tissues, as well 
A

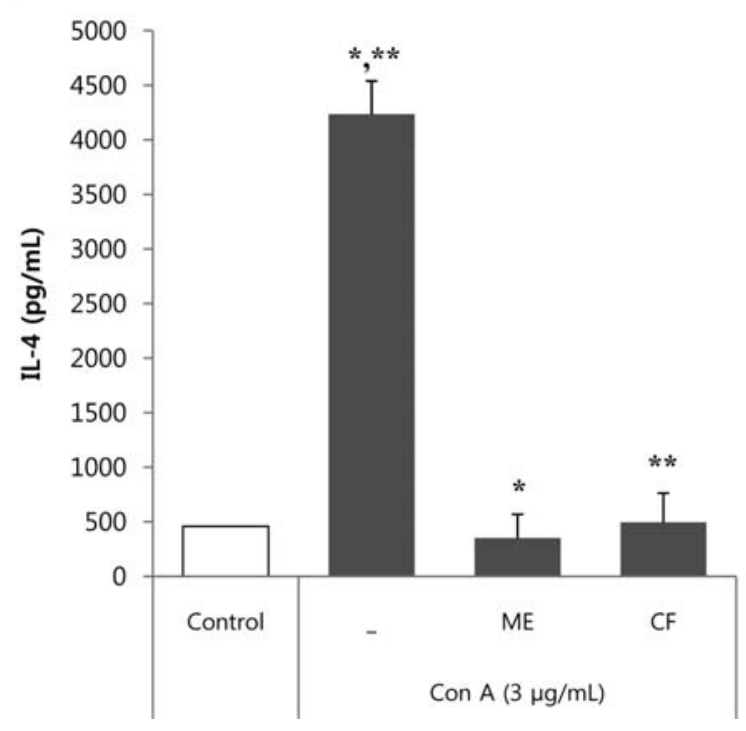

B

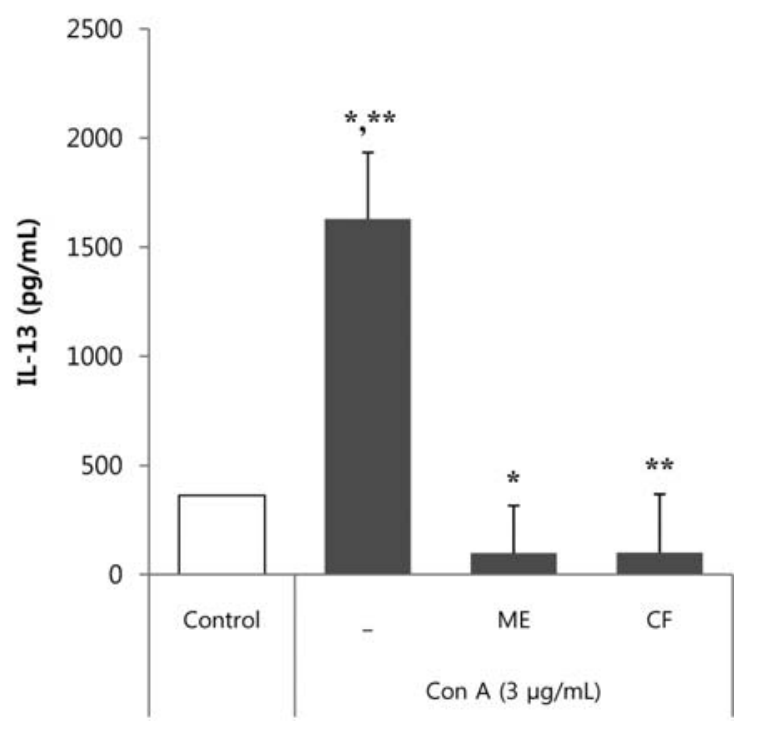

Figure 3. Expressions of cytokines in ovalbumin-induced mice by the treatment of mycelial extract and culture filtrate. Mycelial extract (ME) and culture filtrate (CF) of Cordyceps sphecocephala J201 was treated into ovalbumin-induced mice and analyzed as described in Materials and methods. Measurement of IL-4 (A) and IL-13 (B) content was carried out by ELISA kits. Mouse spleen cells were collected and activated by Concanavalin A (Con A: $3 \mu$ g/ml) to activate the total cells as described in detail in Materials and methods. -, Con A alone; ME, mycelium extract; CF, culture filtrate. Data show mean \pm SD of triplicate determinations. ${ }^{*}$ Significant difference from Con A alone, $\mathrm{P}<0.001 .{ }^{* *}$ Significant difference from Con $\mathrm{A}$ alone, $\mathrm{P}<0.001$.
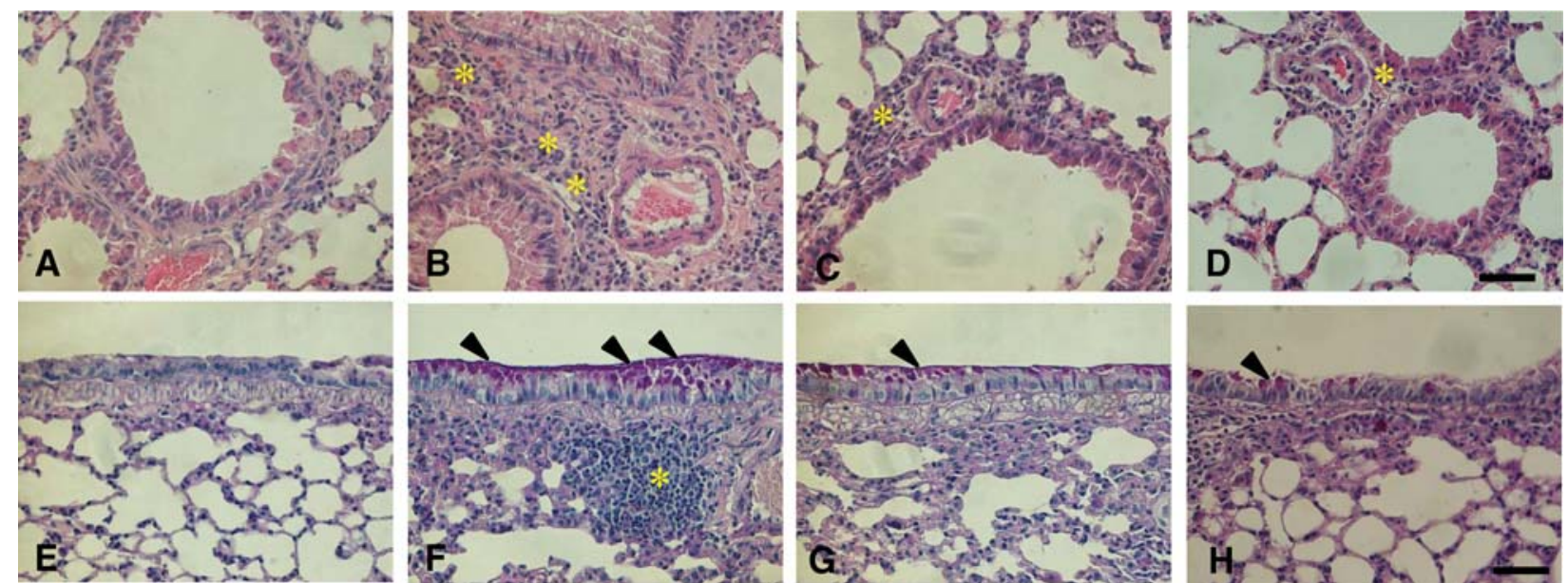

Figure 4. Effects of Cordyceps sphecocephala J201 mycelial extract on histological feature of the lung in mice. Hematoxyline and eosin stained section in the control (A), ovalbumin-induced (B), mycelial extract (C) groups, or montelukast (D). Thin section of the PAS stained epithelial cells around lung tissues with control $(\mathrm{E})$, ovalbumin-induced $(\mathrm{F})$, extract treatment $(\mathrm{G})$ groups, or montelukast treatment $(\mathrm{H})$. Bars indicate $50 \mu \mathrm{m}$. Asterisks represent a classical cell cluster of cell infiltration, and arrowheads indicate mucus production.

as in serum, during hypersensitivity events $(3,10,12)$. Other expressions, such as T-bet, eotaxin, IgE, B-hexosaminidase and histamine will also affect asthmatic symptoms in vivo. In order to investigate whether the mycelium extract and culture broth of Cordyceps sphecocephala J201 have potential in alleviating the asthmatic symptoms in vivo, we activated the asthmatic marker levels, such as IL-4 and IL-13, by ovalbumin in mice.

As shown in Materials and methods, we dispersed ovalbumin by aerosolized spraying in mice, and then administered the mycelial extract and culture broth of the Cordyceps sphecocephala J201 to assess the potential in alleviating the asthmatic symptoms in vivo. All mice were sensitized intraperitoneally with $100 \mu \mathrm{g} /$ head of ovalbumin on days 0 and 12 . The mice were re-exposed to aerosolized ovalbumin or saline for $30 \mathrm{~min}$ on days 25, 27 and 29 . Following treatment with mycelial extract or culture broth of the Cordyceps sphecocephala J201 (50 $\mu \mathrm{g} / \mathrm{head})$ every 2 days for 26 to 30 days, histopathological observations of lung tissues were performed. As a result, hematoxylin and eosin (H\&E) staining showed clean tissue in the control group (Fig. 4A), whereas several immune positive cells were clustered together around the smaller parts of the lungs in the ovalbumin-treated tissues (Fig. 4B and F; asterisks). However, 

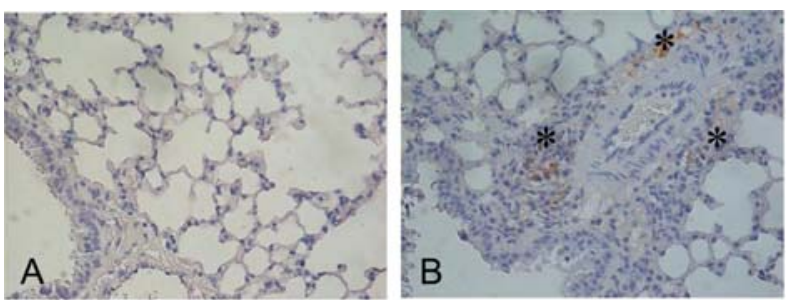

E

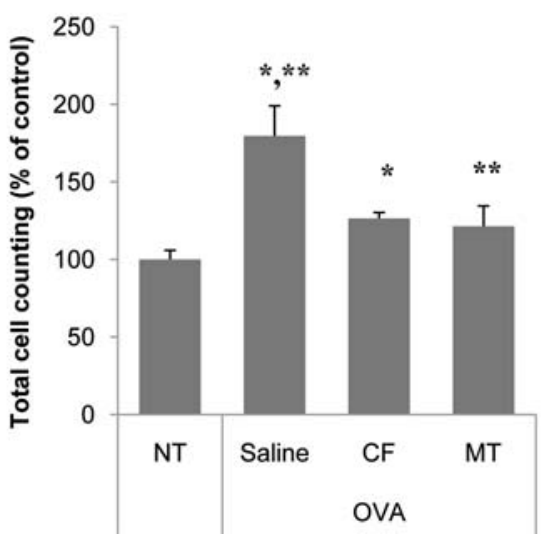

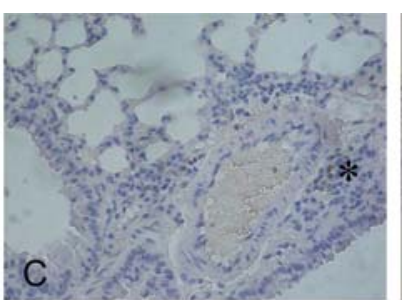

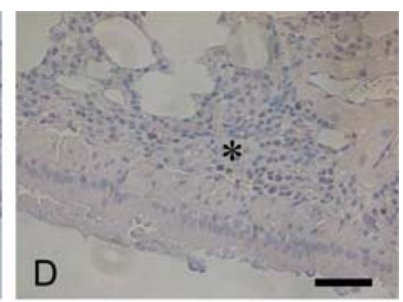

F

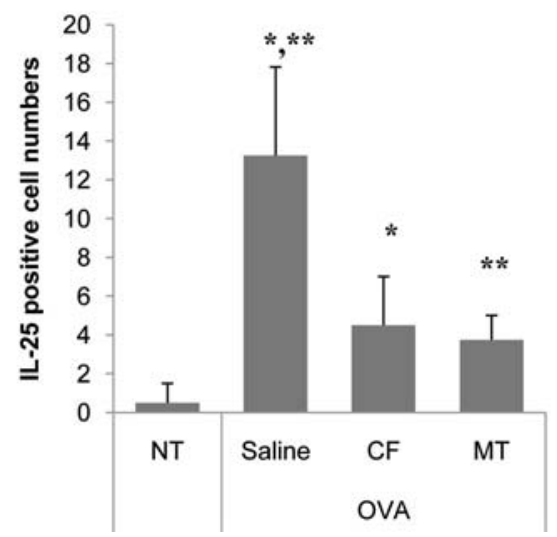

Figure 5. Lung histology of IL-25 expression by treatment of extracts. Immunohistochemical analysis was carried out with (C) or without (B) culture filtrate in ovalbumin-induced mice. In control (A), there is no IL-25 positive cells (no asterisk), whereas tissue of OVA-induced mice (B) has several clumps of IL-25 positive cells. By treatment of culture filtrate (C) or montelukast (D), the positive cell clump was dramatically reduced. In OVA-induced mice, the total immune positive cell counting was achieved (E), and thereafter IL-25 positive cell numbers was counted on the width of 0.1 mm ${ }^{2}$ by immunohistochemistry using IL-25 antibody (F). Bar indicates $50 \mu \mathrm{m}$. Asterisks represent a classical cell cluster of cell infiltration. Data show mean \pm SD of triplicate determinations. *Significant difference from OVA alone, $\mathrm{P}<0.05$. ${ }^{* *}$ Significant difference from OVA alone, $\mathrm{P}<0.05$.

the number of total immune positive cells from the ovalbumin-challenged group that were treated with the mycelial extract (50 $\mu \mathrm{g} /$ head) had decreased dramatically, as compared with that of ovalbumin-challenged lung tissues (Fig. 4C). As a positive control, we used montelukast, a worldwide used anti-asthmatic drug, and examined whether the extract has potential in alleviating asthmatic symptoms compared to montelukast.

As shown in Fig. 4D and $\mathrm{H}$, the tissues were clear and clean, and there were mere asthmatic signs, which means the OVA-induced lung tissues were protected by the extracts. The above results clearly showed that the anti-asthmatic activities in extracts exert protective effects on OVA-induced damage. Periodic acid-Schiff (PAS) staining show similar aspects (Fig. 4E-H) to those gained with the H\&E staining, while disclosing potent mucus secretions (Fig. 4F, arrowhead). We also measured the $\mathrm{CD}^{+}$cell content by immunohistopathological analysis, but remarkable changes were not evident in the lung tissues (data not shown).

IL-25 (IL-17E), a novel IL-17 family of immunomodulatory cytokines, is a product of activated Th2 cells. The IL-25 mRNA is expressed in the lung after an engulfed antigen challenge of sensitized mice and the neutralization of the released IL-25 by soluble IL-25 receptor reduced antigen-induced eosinophil/macrophages on airway hyperresponsiveness and inflammation (34-36). Next, we evaluated whether or not the ovalbumin-inhaled lung tissues were rescued from IL-25 expression by the treatment of Cordyceps sphecocephala J201 extracts. Immunohistochemical observations revealed that the IL-25 positive cells were significantly dispersed around the ovalbumin-treated tissues (Fig. 5B; asterisks), whereas the extract as well as montelukast treatment had dramatically reduced the number of positive cells (Fig. 5C and D). IL-25 positive cell counting revealed that the extract treatment of Cordyceps sphecocephala significantly reduced IL-25 secreting cells (Fig. 5F), suggesting that activated Th2 cells were modulated in balance with the Th1/Th2 cell subset (See 3rd column).

We performed reverse transcription-polymerase chain reaction (RT-PCR) using the primers (TGGCTGAAGTGGA GCTCTGC and TGGCAAGGTGATTGTACACCTG; 464 bp of gene product) for the mRNA expression, and measured the reduced expression (data not shown). Montelukast also inhibited the number of IL-25 positive cells (Fig. 5F, 4th column). These results clearly matched the total cell counting numbers which respond to H\&E staining (Fig. 5E), which is one of the classical feature of the OVA-induced inflammation. This was the first data that showed IL-25 levels induced by ovalbumin could be alleviated by the addition of Cordyceps sphecocephala J201 extracts. Fig. 5D shows one of the classical results to the reduction of ovalbumin-induced inflammation.

In conclusion, in this study, we investigated whether the functional biomaterials in the extracts can be effective for asthma, suggesting that mycelial extract and culture filtrate of Cordyceps sphecocephala J201 had the potential of 
alleviating immune hypersensitivity reactions in asthma. Asthmatic animal models exhibited decreased level of immune responses with $\mathrm{T}$ cells that are associated with molecular inflammation. The isolation, purification, characterization of active components/compounds against asthmatic symptoms that are needed for the development of food biomaterials and/or nutraceuticals could be useful for further investigations.

\section{Acknowledgements}

This study was supported by BioGreen 21 (Agenda) Projects, RDA, Korea (2009101-060-005-001-02-00), and was also supported in part by Technology Development Program for Agriculture and Forestry, Ministry for Food, Agriculture, Forestry and Fisheries, Republic of Korea.

\section{References}

1. Vliagoftis $\mathrm{H}$ and Forsythe P: Should we target allergen protease activity to decrease the burden of allergic airway inflammation? Inflamm Allergy Drug Targets 7: 288-295, 2008.

2. Stone KD and Prussin C: Immunomodulatory therapy of eosinophil-associated gastrointestinal diseases. Clin Exp Allergy 38: 1858-1865, 2008.

3. Nouri-Aria KT and Durham SR: Regulatory T cells and allergic disease. Inflamm Allergy Drug Targets 7: 237-252, 2008.

4. Rabin RL and Levinson AI: The nexus between atopic disease and autoimmunity: a review of the epidemiological and mechanistic literature. Clin Exp Immunol 153: 19-30, 2008.

5. Walton RP and Johnston SL: Role of respiratory viral infections in the development of atopic conditions. Curr Opin Allergy Clin Immunol 8: 150-153, 2008.

6. Adcock IM, Chou PC, Durham A, Ford P, Sethi GR and Singhal KK: Overcoming steroid unresponsiveness in airways disease. Biochem Soc Trans 37: 824-829, 2009.

7. Foster JM, Sanderman R, van der Molen T, Mueller T and van Sonderen E: Personality influences the reporting of side effects of inhaled corticosteroids in asthma patients. J Asthma 45: 664-669, 2008

8. de Weck AL, Gamboa PM, Esparza R and Sanz ML: Hypersensitivity to aspirin and other nonsteroidal anti-inflammatory drugs (NSAIDs). Curr Pharm Des 12: 3347-3358, 2006.

9. Leimgruber A: Allergic reactions to nonsteroidal antiinflammatory drugs. Rev Med Suisse 4: 100-103, 2008.

10. Moynihan BJ, Tolloczko B, El Bassam S, et al: IFN-gamma, IL-4 and IL-13 modulate responsiveness of human airway smooth muscle cells to IL-13. Respir Res 9: 84-89, 2008.

11. Ohga K, Kuromitsu S, Takezawa R, Numazaki M, et al: YM-341619 suppresses the differentiation of spleen $\mathrm{T}$ cells into Th2 cells in vitro, eosinophilia, and airway hyper-responsiveness in rat allergic models. Eur J Pharmacol 590: 409-416, 2008.

12. Versluis M, Postma DS, Timens W and Hylkema MN: Effects of IL-4 and IL-13 on adenosine receptor expression and responsiveness of the human mast cell line 1 . Int Immunopharmacol 8: 866-873, 2008.

13. Zhang C, Zou X, Leluo G, Xu J and Xiang M: Prevention of type 1 diabetes by immature dendritic cells treated with an ethanol extract of Paecilomyces hepiali Chen mycelium. Methods Find Exp Clin Pharmacol 30: 421-429, 2008.

14. Oh JY, Baek YM, Kim SW, Hwang HJ, et al: Apoptosis of human hepatocarcinoma (HepG2) and neuroblastoma (SKN-SH) cells induced by polysaccharides-peptide complexes produced by submerged mycelial culture of an entomopathogenic fungus Cordyceps sphecocephala. J Microbiol Biotechnol 18: 512-519, 2008 .
15. Koh JH, Kim JM, Chang UJ and Suh HJ: Hypocholesterolemic effect of hot-water extract from mycelia of Cordyceps sinensis. Biol Pharm Bull 26: 84-87, 2003.

16. Wu JY, Zhang QX and Leung PH: Inhibitory effects of ethyl acetate extract of Cordyceps sinensis mycelium on various cancer cells in culture and B16 melanoma in C57BL/6 mice. Phytomedicine 14: 43-49, 2007.

17. Wang ZS, Gu YX and Yuan QS: Effect of nutrition factors on the synthesis of superoxide dismutase, catalase, and membrane lipid peroxide levels in Cordyceps militaris mycelium. Curr Microbiol 52: 74-79, 2006.

18. Chien CC, Tsai ML, Chen CC, Chang SJ and Tseng CH: Effects on tyrosinase activity by the extracts of Ganoderma lucidum and related mushrooms. Mycopathologia 166: 117-120, 2008.

19. Ji DB, Ye J, Li CL, Wang YH, Zhao J and Cai SQ: Anti-aging effect of Cordyceps sinensis extract. Phytother Res 23: 116-122, 2009.

20. Shi B, Wang Z, Jin H, Chen YW, Wang Q and Qian Y: Immunoregulatory Cordyceps sinensis increases regulatory $\mathrm{T}$ cells to Th17 cell ratio and delays diabetes in NOD mice. Int Immunopharmacol 9: 582-586, 2009.

21. Ko WS, Hsu SL, Chyau CC, Chen KC and Peng RY: Compound Cordyceps TCM-700C exhibits potent hepatoprotective capability in animal model. Fitoterapia 81: 1-7, 2010.

22. Ohta Y, Lee JB, Hayashi K, Fujita A, Park DK and Hayashi T: In vivo anti-influenza virus activity of an immunomodulatory acidic polysaccharide isolated from Cordyceps militaris grown on germinated soybeans. J Agric Food Chem 55: 10194-10199, 2007.

23. Nishizawa K, Torii K, Kawasaki A, et al: Antidepressant-like effect of Cordyceps sinensis in the mouse tail suspension test. Biol Pharm Bull 30: 1758-1762, 2007.

24. Hsu CH, Sun HL, Sheu JN, et al: Effects of the immunomodulatory agent Cordyceps militaris on airway inflammation in a mouse asthma model. Pediatr Neonatol 49: 171-178, 2008.

25. Nam SH, Li CR, Hong IP, Sung KB, Kang SW, Fan MZ and $\mathrm{Li} \mathrm{ZZ}$ : Isolation and culture of entomopathogenic fungus, Cordyceps sphecocephala. Int J Indust Entomol 13: 57-61, 2006.

26. Heo JC, Nam SH, Yeo JH, et al: Immunomodulating activities in mycelia filtrates and culture broth of Cordyceps ochraceostromat. Kor J Food Preserv 16: 253-258, 2009.

27. Soylu S, Yigitbas H, Soylu EM and Kurt S: Antifungal effects of essential oils from oregano and fennel on Sclerotinia sclerotiorum. J Appl Microbiol 103: 1021-1030, 2007.

28. Heo JC, Woo SU, Kweon MA, et al: Aqueous extract of the Helianthus annuus seed alleviates asthmatic symptoms in vivo. Int J Mol Med 21: 57-61, 2008.

29. An SM, Park CH, Heo JC, et al: Gastrodia elata Blume protects against stress-induced gastric mucosal lesions in mice. Int $\mathrm{J}$ Mol Med 20: 209-215, 2007.

30. Heo JC, Rho JR, Kim TH, Kim SY and Lee SH: An aqueous extract of green tea Camellia sinensis increases expression of Th1 cell-specific anti-asthmatic markers. Int J Mol Med 22: 763-767, 2008.

31. Caruso R, Sarra M, Stolfi C, et al: Interleukin-25 inhibits interleukin-12 production and Th1 cell-driven inflammation in the gut. Gastroenterology 136: 2270-2279, 2009.

32. Crimi N, Palermo F, Polosa R, et al: Effect of indomethacin on adenosine-induced bronchoconstriction. J Allergy Clin Immunol 83: 921-925, 1989.

33. Chen Z, Soo MY, Srinivasan N, Tan BK and Chan SH: Activation of macrophages by polysaccharide-protein complex from Lycium barbarum L. Phytother Res 23: 1116-1122, 2009.

34. Angkasekwinai $\mathrm{P}$, Park $\mathrm{H}$, Wang $\mathrm{YH}$, et al: Interleukin 25 promotes the initiation of proallergic type 2 responses. J Exp Med 204: 1509-1517, 2007.

35. Ballantyne SJ, Barlow JL, Jolin HE, et al: Blocking IL-25 prevents airway hyperresponsiveness in allergic asthma. J Allergy Clin Immunol 120: 1324-1331, 2007.

36. Tamachi T, Maezawa Y, Ikeda K, Iwamoto I and Nakajima H: Interleukin 25 in allergic airway inflammation. Int Arch Allergy Immunol 140 (Suppl 1): 59-62, 2006. 